\title{
Assessment of meteorological droughts over Saudi Arabia using surface rainfall observations during the period 1978-2017
}

\author{
Mansour Almazroui ${ }^{1}$
}

Received: 23 November 2018 / Accepted: 3 October 2019 / Published online: 15 November 2019

(C) The Author(s) 2019

\begin{abstract}
This paper discusses the preliminary results of meteorological drought analysis over Saudi Arabia for the period 1978-2017. In conjunction with meteorological observations, datasets from the Climate Prediction Center (CPC), the Merged Analysis of Precipitation (CMAP), the Climatic Research Unit (CRU), and the Tropical Rainfall Measuring Mission (TRMM) are utilized to understand the impact of the spatial distribution of rainfall on drought events. Applying precipitation thresholds allows rainfall classifications such as deficit, scanty, and surplus. Precipitation thresholds are also used to define meteorological droughts in the country, which are categorized as usual, moderate, and severe. It is found that drought events occur in Saudi Arabia due to shortfalls in the dry season, even though there is above normal rainfall in the wet season. There is no case of a shortfall in both the wet and dry seasons causing drought. Saudi Arabian droughts of all categories occurred mostly in the dry season, with fewer in the wet season. Results show that in Saudi Arabia, the last month of the wet season (April) is less prone to drought while the first and last months of the dry season (June and September respectively) are more prone to drought. Spatial distribution of drought climatology is obtained by calculating the Standardized Precipitation Index (SPI) and the Palmer Drought Severity Index (PDSI). Further application-driven studies of projections are needed based on drought indices and climate model output.
\end{abstract}

Keywords Drought $\cdot$ Rainfall $\cdot$ Saudi Arabia $\cdot$ Precipitation threshold $\cdot$ Observed and gridded datasets

\section{Introduction}

Drought is a recurrent characteristic feature of climate variability and is manifest by prolonged and continuous periods of dry weather along with an abnormal deficient of rainfall. Droughts have significant impacts on the infrastructure, socio-economic activity, and the environment. They cause drying of the earth and water shortages, dry wells, depletion of groundwater and soil moisture, stream flow reduction, crop failure, and a lack of fodder for livestock. These impacts are particularly severe on already semi-arid and arid regions (Abdullah and Al-Mazroui 1998; Ragab and Prudhomme 2000) such as the Arabian Peninsula, and in particular on Saudi Arabia, which covers $80 \%$ of the Peninsula (Almazroui et al. 2012a, 2012b). Saudi

Responsible Editor: Zhihua Zhang

Mansour Almazroui mansour@kau.edu.sa

1 Center of Excellence for Climate Change Research / Department of Meteorology, King Abdulaziz University, P.O. Box 80208, Jeddah 21589, Saudi Arabia
Arabia contains the world's largest continuous sand desert, the Rub Al-Khali (Empty Quarter). Despite the fact that both the onset and the ending of droughts are usually slow processes, their cumulative effect can be far more disastrous than other climate phenomena, (Bhalme and Mooley 1980). The total impact of large-scale droughts may be far more disastrous than other short time scale natural phenomena even catastrophic ones such as floods (Bhalme and Mooley 1980). Cumulatively, droughts have direct negative impacts on various socio-economic sectors including agriculture, food production, infrastructure, biodiversity, tourism, and water storage.

Precipitation is the single most influential meteorological variable on the persistence and ending of drought, although drought can manifest itself in different ways, e.g., food shortages, water scarcity, and difficulties with power generation. Other variables, both meteorological (e.g., surface temperature, moisture and cloud cover) and hydrological (e.g., soil moisture, evapotranspiration, runoff and underground water table), are of secondary importance in the characterization of drought. Both meteorological and hydrological variables are non-stationary in historical records due to climate change and global warming. The 
Intergovernmental Panel for Climate Change (IPCC) has declared that the warming of our climate, observed since the beginning of the 20th century, is unequivocal (IPCC 2007, 2013). The consequences of this warming have been observed in the recent decades. For example, changes in atmospheric circulation and rainfall patterns and the widening of the tropical belt are commonly accepted as consequences of global warming (Seidel et al. 2008). It is expected that climate change will continue to affect rainfall patterns and hence the frequency and intensity of droughts in the future. Therefore, understanding drought situations in the present climate is a prerequisite to the analysis of any future scenarios.

The Arabian Peninsula, like many other places, is experiencing changes in temperature and rainfall patterns in response to climate change which will significantly affect the frequency and spatial characteristics of droughts. Unprecedented changes in the climate of Saudi Arabia have been reported by Almazroui et al. (2012a) in recent years. The trend of increasing global surface temperature is also observed regionally in the various districts of Saudi Arabia (Almazroui et al. 2012b). The observed surface temperatures in Saudi Arabia have been analyzed by Almazroui et al. (2012a) and were found to display a significant increasing trend. They also report a significant trend of decreasing rainfall for the recent past (1994-2009). It is expected that this warming trend will also have an impact on rainfall and probably on drought (Almazroui et al. 2012b). Rainfall climatology, particularly in an arid environment, is strongly governed by the topography (Lioubimtseva 2004). From analysis of rainfall climatology, Almazroui et al. (2012a) concluded that there is great spatial and temporal diversity of rainfall over the Arabian Peninsula.

Although many research centers have conducted drought studies in various locations worldwide, to the best of our knowledge, very little research has been done in this field for Saudi Arabia. For example, the Red Cross/Red Crescent Climate Centre in the Netherlands reported on East African drought (Shongwe et al. 2011), the European Drought Center (http://europeandroughtcentre.com/about-us/edc/), the Queensland Drought Mitigation Centre in Australia (http:// www.droughtmanagement.info/wp-content/uploads/2017/08/ 1_9_International-Drought-Mitigation-Research-Center 2017.pdf), and the North Central Climate Science Center and NOAA's Physical Sciences Division in USA (https://casc. usgs.gov/content/eddi-new-drought-index-provides-earlywarning-flash-droughts) all work locally and internationally on this topic. To comply with the Water and Environment National Programs proposed by the King Abdulaziz City for Science and Technology (KACST), to face the challenges posed by future climate change and to contribute to timely and evidence-based decision-making, we have undertaken research to fill this knowledge gap, and specially to identify drought characteristics over Saudi Arabia. Therefore, the main goal of this paper is to identify the principal characteristics of drought events in Saudi Arabia using observed and gridded datasets for the present climate and to improve understanding of seasonal impacts on the identified events.

\section{Data and methodology}

There are three types of droughts: namely meteorological, hydrological, and agricultural. In this study, we focus on meteorological drought over Saudi Arabia by analyzing the observed rainfall and its distribution patterns. It is possible to diagnose meteorological drought by analyzing the rainfall time series. For this purpose, the following datasets are used:

a) Observations of available monthly surface rainfall collected by the General Authority of Meteorological and Environmental Protection (GAMEP; hereafter referred to as observed) for the period 1978-2017. The observation locations in Saudi Arabia are shown in Fig. 1 (open circles). The GAMEP data have the advantage of being quality controlled (Islam et al. 2015).

b) Gridded datasets from the Climate Prediction Center (CPC) Merged Analysis of Precipitation (CMAP; see Xie and Arkin 1997), the Climatic Research Unit (CRU; see Harris et al. 2014; Mitchell et al. 2004; New et al. 2000), and the Tropical Rainfall Measuring Mission (TRMM; see Kummerow et al. 2000).

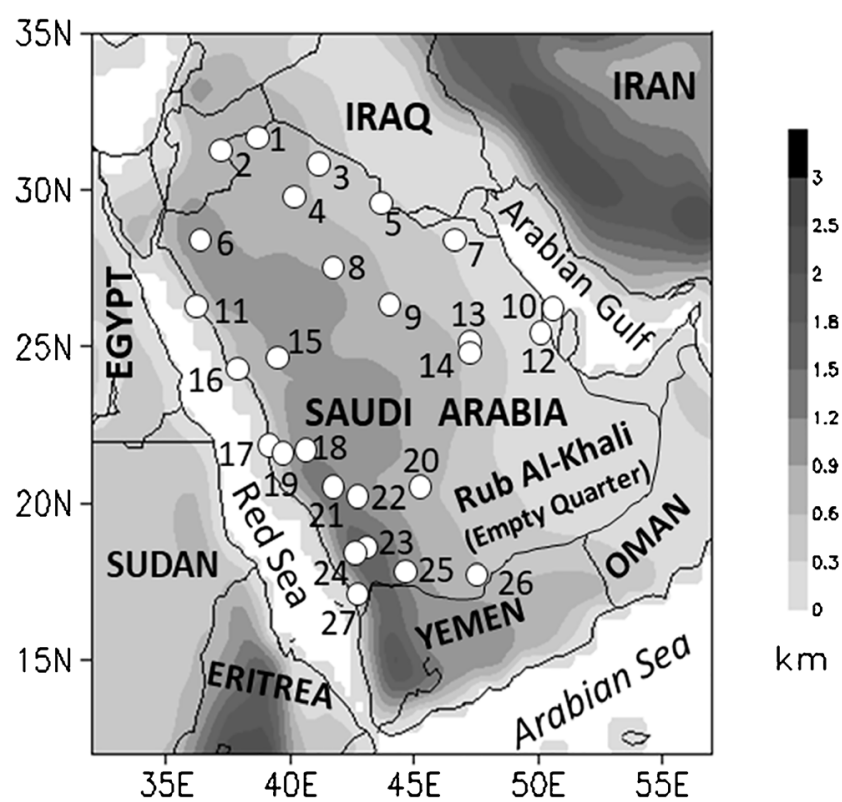

Fig. 1 The map of Saudi Arabia and its surroundings with elevation (km). The surface observation sites throughout Saudi Arabia are shown with open circle marks. The numeric represents station ID from north to south across the country and stations names can be seen in Almazroui et al. (2012a) 
While various definitions of drought have been formulated in the literature over the past 30 to 50 years, there is still no single universal definition of drought. In this study, the focus is mainly on meteorological drought based on a percent or proportion of normal rainfall (the long-term mean is taken to be $100 \%$ ). In meteorological terms, drought is in general associated with a prolonged and abnormal regional moisture deficit (Palmer 1965) or a sustained period of significantly below normal rainfall (Oladipo 1985). The definition of drought is also dependent on the region of interest, for example, as pointed out by Oladipo (1985), a dry period of several weeks in the mid-latitudes in the summer can be considered to be a drought, whereas in other areas, such as parts of the subtropics, drought is normally defined as two or more consecutive rainy seasons without rain. Similar definitions aligned with rainfall thresholds are used in different parts of the world, e.g., in India, South Africa, and USA (Smakhtin and Hughes 2004).

Annual rainfall of $25 \%$ or monthly rainfall of $40 \%$ below normal is suggested to define drought in the USA (Bates 1935). Droughts in South Africa are defined as rainfall below $50 \%$ of the normal amount (Bruwer 1990). In some states of India, seasonal (or even weekly) rainfall below $50 \%$ of normal is accepted to constitute drought conditions (Banerji and Chabra 1964; Ramdas 1950). However, the Indian Meteorological Department (IMD) defines a deficit as 20$60 \%$ less rain than normal while scanty is defined as more than $60 \%$ below normal. In general, meteorological droughts in India are defined (Smakhtin and Hughes 2004) as follows: usual or common drought (rainfall in a month/season is $\geq 25 \%$ below normal), moderate drought (between 26 and $50 \%$ below normal), and severe drought ( $\geq 50 \%$ below normal). However, the question arises as to how to define and analyze meteorological drought for a semi-arid to arid climate region such as Saudi Arabia? To answer this question, we first analyze dry conditions based on rainfall thresholds. Next, drought indices are calculated, and a few drought cases are studied in detail for better understanding any seasonal factors behind drought in Saudi Arabia. The final goal is to calculate drought indices from climate model output data, which will be documented separately.

In this analysis, categories of rainfall are defined as follows: average (simple average from all stations used), deficit ( $\geq 20 \%$ below normal), and scanty ( $\geq 60 \%$ below normal). The categories of surplus ( $\geq 20 \%$ above normal) and usual (within $\pm 20 \%$ of normal) are also used. Monthly rainfall data are used for annual and seasonal analyses, and the national average is based on data from all 27 stations across the country. The annual rainfall duration is defined as the ratio of rainy years to the total analysis period expressed as a percentage and trend significance is obtained using $F$ test.

To better understand the drought situation in Saudi Arabia, drought indices (for instance see Dash et al. 2012; Gidey et al. 2018a,b; Mustafa and Rahman 2018) were calculated for the long-term over the country. Among various drought indices, we selected the Standardized Precipitation Index (SPI, Mckee et al. 1993) and the Palmer Drought Severity Index (PDSI, Palmer 1965) to be calculated using observed rainfall from 27 stations, along with other variables for the current climate. The drought events may be categorized using the SPI values as follows: mild ( 0 to -0.99$)$, moderate $(-1.00$ to -1.49$)$, severe $(-1.50$ to -1.99$)$, and extreme $(-2.00$ and less). In PDSI, drought events are categorized as mild drought ( -1.0 to 1.99), moderate drought ( -2.0 to -2.99$)$, severe drought (3.0 to -3.99$)$, and extreme drought $(-4.0$ or less).

The topography of Saudi Arabia and its surroundings is shown in Fig. 1. A northwest-southeast-oriented mountain range with heights reaching about $1.5 \mathrm{~km}$ or more above sea level is located on the southwestern side of Saudi Arabia crossing through to Yemen (Fig. 1). This complex mountainous region receives the highest annual mean rainfall in Saudi Arabia (Almazroui 2011).

The observed data currently available over Saudi Arabia is mainly from stations along the western and eastern coasts and the northern and central areas of the country. There are no station data available from the southeastern region where Rub Al-Khali or the Empty Quarter is situated. In this paper, the definition of wet (November to April) and dry (June to September) seasons are adopted following Almazroui (2011), consistent with the climatology of Saudi Arabia. This study used May and October as transition periods from wet to dry and dry to wet, respectively.

We first analyzed the observed rainfall time series data to identify drought years using rainfall thresholds. Then, the reanalysis gridded datasets were examined to understand the influence of seasonal rainfall on the drought events. The higher resolution $\left(0.25^{\circ} \times 0.25^{\circ}\right)$ gridded rainfall dataset Tropical Rainfall Measuring Mission (TRMM) starting from 1998 was available for analysis. A relatively coarse resolution $\left(2.5^{\circ} \times 2.5^{\circ}\right)$ gridded rainfall dataset was available from CMAP, starting in 1979 (both over land and the ocean), as well as from $\mathrm{CRU}\left(0.5^{\circ} \times 0.5^{\circ}\right)$ for land only. In this study, the CMAP, CRU, and TRMM datasets are employed to investigate the causes of drought in the rain-deficit years identified by the time series analysis mentioned earlier. Note that these gridded datasets are already calibrated against the observed rainfall and good agreement was found among the datasets (Almazroui et al. 2012a).

\section{Results}

\section{Rainfall categories for Saudi Arabia}

Annual rainfall duration (defined as rainy year divided by total 40 analyzed year expressed as a \%) varies from category to 
Fig. 2 Annual rainfall duration (percent of the rainy year to the analysis period) associated to different categories at each station location across Saudi Arabia for the period 1978-2017. Different categories are identified based on rainfall threshold. Station IDs are followed according to Fig. 1

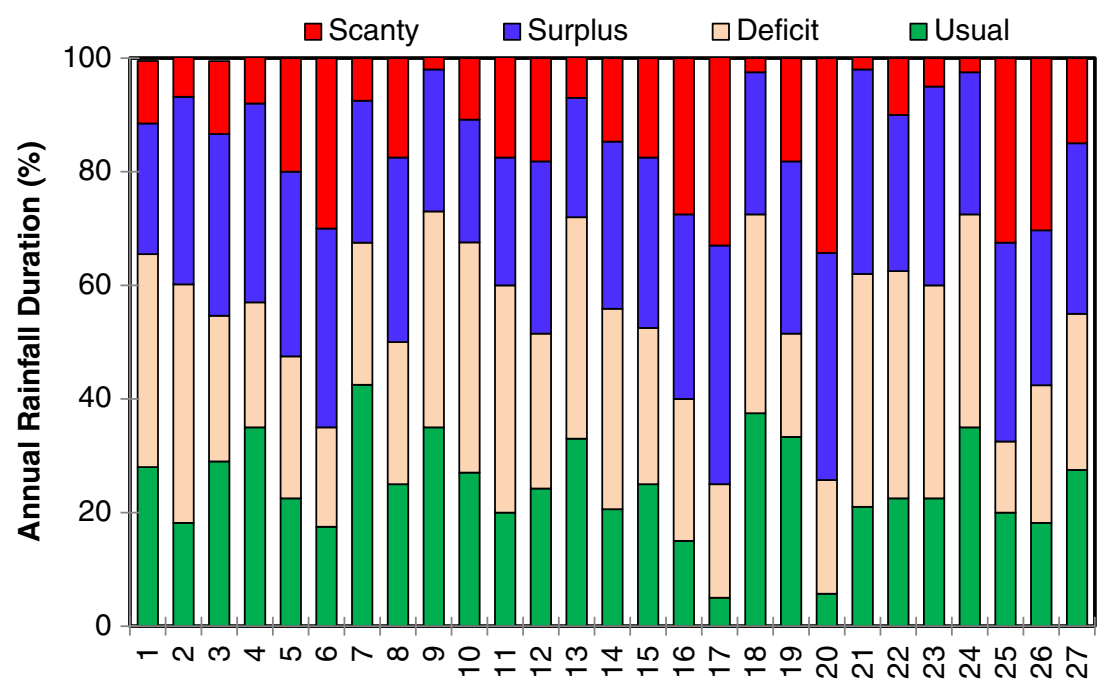

Stations category and station to station (Fig. 2). Large variations in annual rainfall duration are found between stations for the categories of usual and scanty rainfall. The category of usual rainfall is the most frequent one for the northeast station 7
Fig. 3 Time sequences of the number of stations (in percent) associated with different rainfall classes in Saudi Arabia for the period 1978-2017

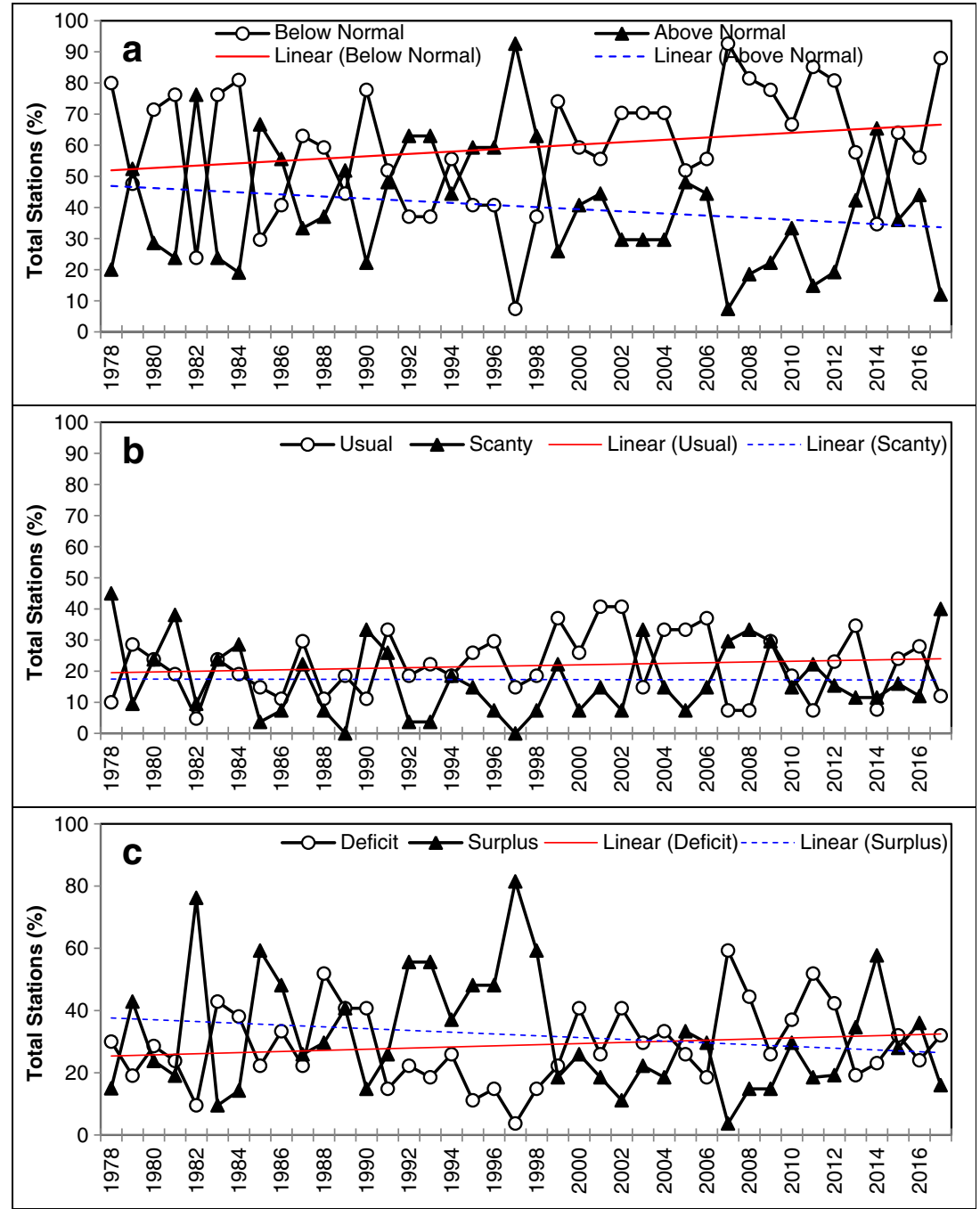


Fig. 4 The time sequences of a annual, $\mathbf{b}$ wet season, and $\mathbf{c}$ dry season rainfall $(\mathrm{mm})$ with their classes obtained from the observed dataset. The normal (country average from 27 stations), deficit ( $20 \%$ below normal), scanty ( $60 \%$ below normal), and surplus (within $\pm 20 \%$ of normal) are used to identify drought year over the country
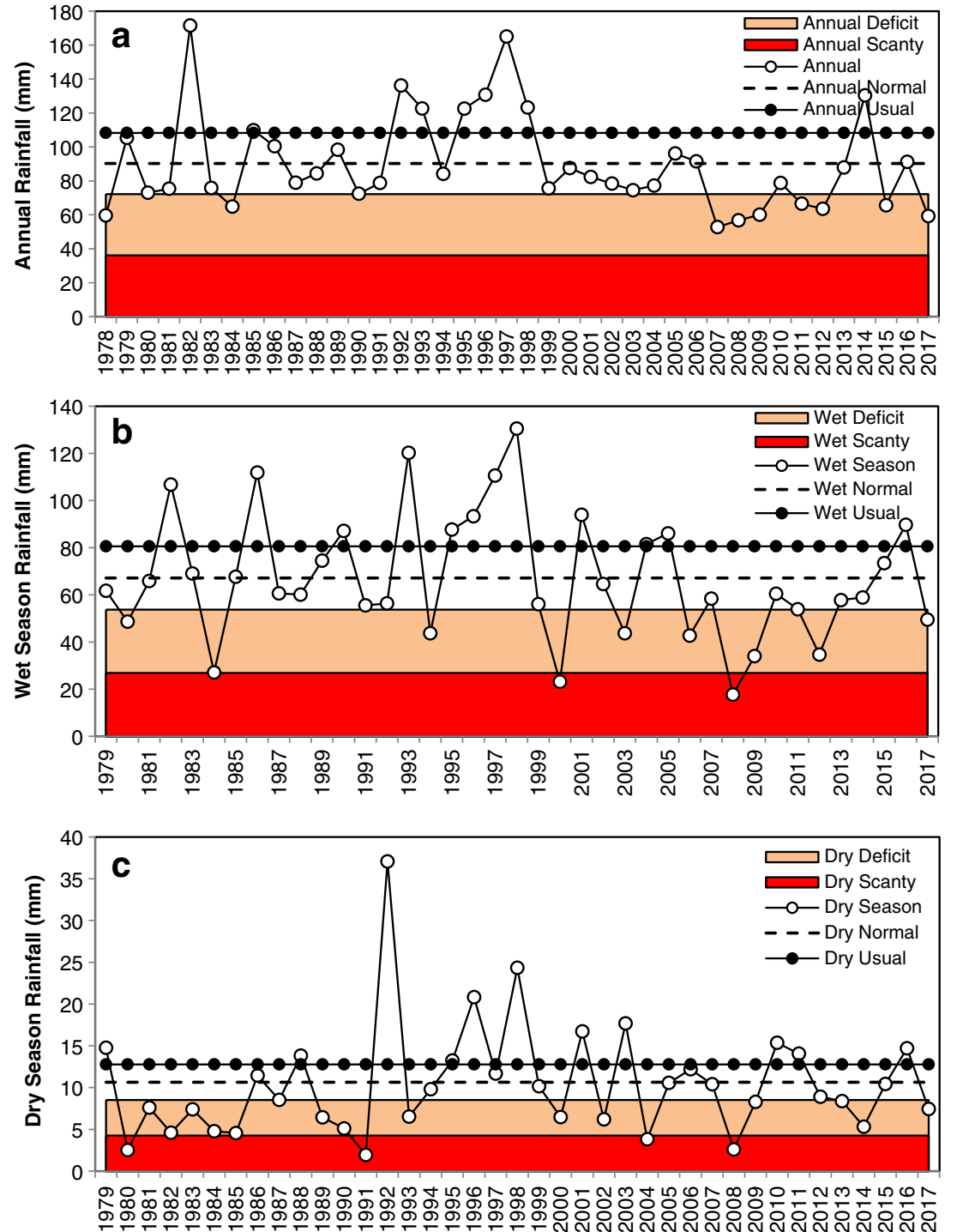

(AlQuasumah) (43\%, 17 years out of 40), whereas it is least frequent for the western station 17 (Jeddah) (5\%, 2 years out of 40). In contrast, the category of scanty rainfall duration is found to be most common for station $17(37 \%)$ and least usual (3\%) for stations 9,18 , and 24 . The abundance of the category of deficit rainfall duration is almost the same for all stations except for a few, the lowest being $13 \%$ for the southern station 25 (Najran). In general, the deficit rainfall category is rarer for those stations with many surplus and scanty years, e.g., stations 6 and 25 .

Time sequences of the stations (in \%) across Saudi Arabia associated with different rainfall categories are shown in Fig. 3. As shown in Fig. 3a, the stations with below and above annual normal rainfall years mirror each other: an increase of below-normal rainfall in a year follows a decrease of above-normal in the same year and vise versa. The number of stations with above normal annual rainfall years decreases insignificantly, just as the number with below-normal rainfall increases. Over the analysis period 1978-2017, 58\% of the stations show below-normal rainfall while $42 \%$ show above-normal rainfall. The number of stations showing scanty rainfall decreases insignificantly, while those showing normal or usual rainfall increase (Fig. 3b). Similarly, the number of stations showing a surplus decreases insignificantly, while the number showing a deficit is significantly increases (Fig. 3c) (at the 90\% level). Altogether, this is an indicator of decreased rainfall over the country in recent decades.

The time sequences of annual and seasonal rainfall averaged from all 27 stations over Saudi Arabia are displayed in Fig. 4. In some years, annual rainfall is below normal (dashed line), indicating the possibility of a drought year. Figure 4 a shows that annual rainfall is below normal for 25 years and in deficit for 10 (1978, 1984, 1990, 2007, 2008, 2009, 2011, 2012, 2015, and 2017) of the 40 years from 1978 to 2017. None of the years fall into the scanty rainfall category at the 
a Annual 1998

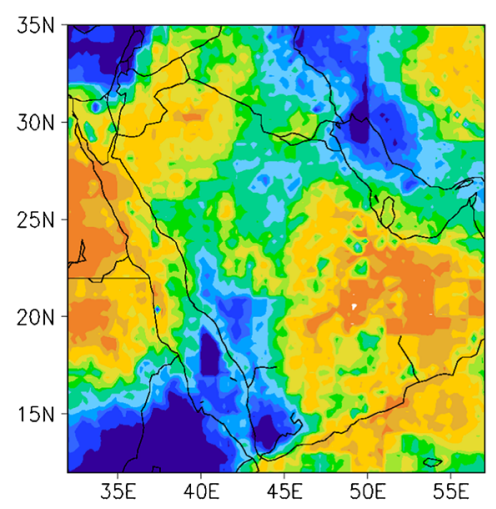

d Wet season 1998

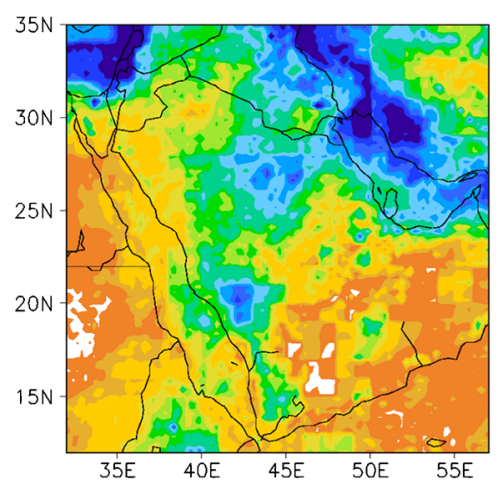

g Dry Season 1998

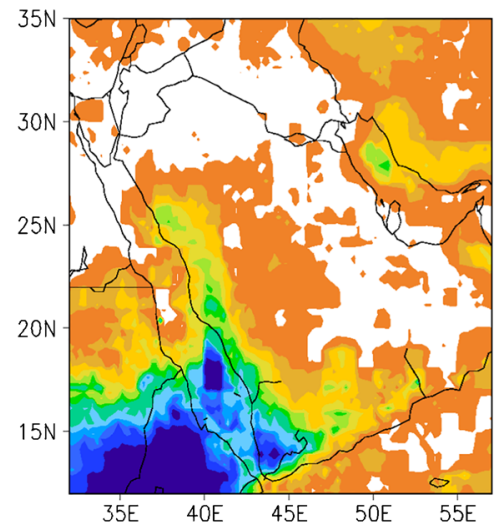

b Annual 1999

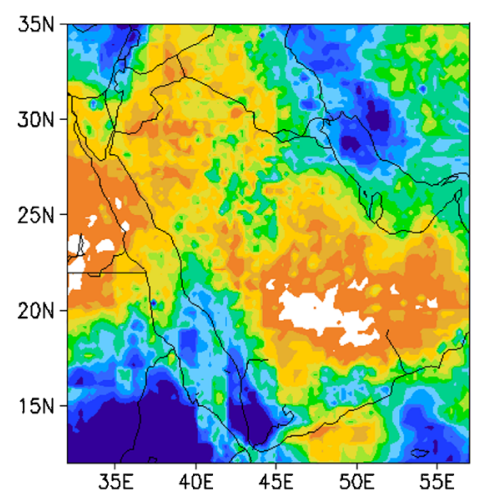

e Wet season 1999

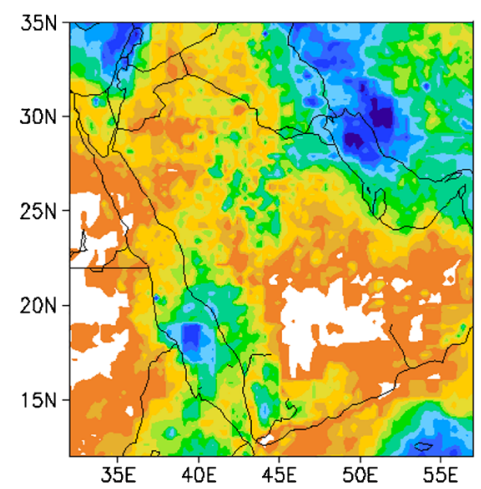

h Dry Season 1999

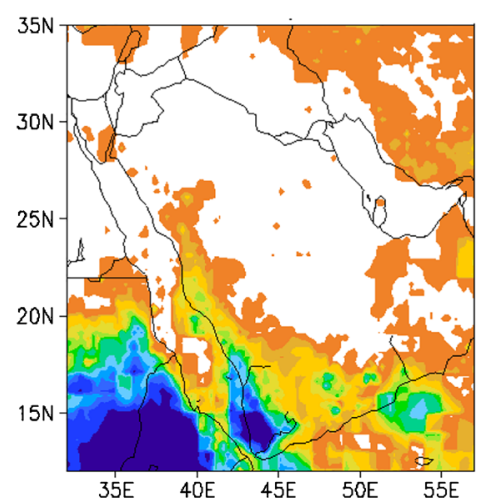

C Annual 2000

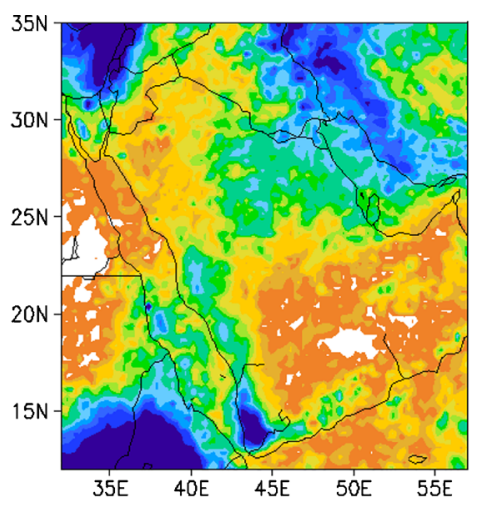

f Wet season 2000

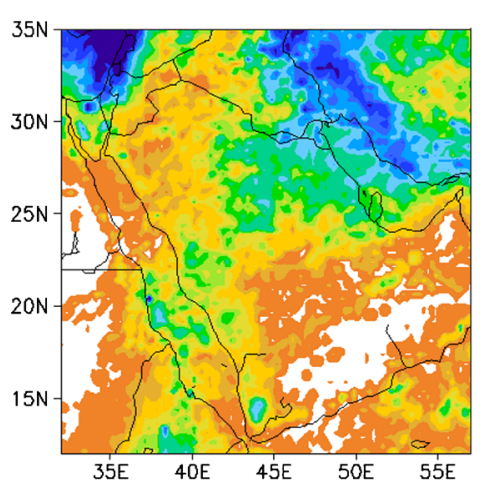

i Dry Season 2000

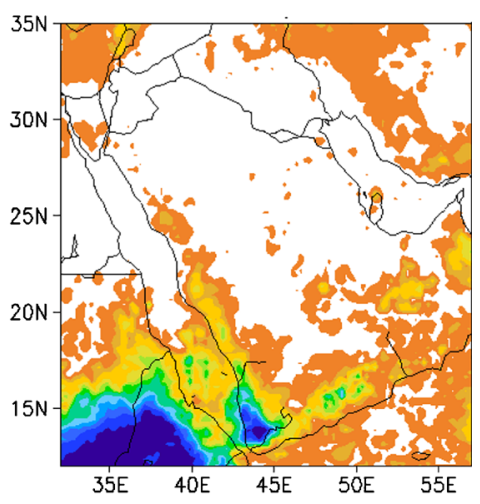

\section{$1 \quad 10 \quad 20 \quad 40 \quad 60 \quad 80 \quad 100150200 \quad 250 \quad 300400$}

Fig. 5 Rainfall obtained from the TRMM dataset for annual (top panels), wet season (middle panels), and dry season (bottom panels) for surplus year 1998 (a, d, g), normal year 1999 (b, e, h) and shortfall year 2000 (c, f, i). Rainfall amount below $1 \mathrm{~mm}$ is not shown in the legend

annual scale. In the wet season, there are many years with below-normal rainfall of which 7 (1980, 1994, 2003, 2006, 2009, 2012, and 2017) are identified as being in deficit (Fig. 4b). The rainfall analysis of the wet season identified that 3 years $(1984,2000$, and 2008) as scanty. This indicates that there was very little rainfall in the wet season over the country for these 3 years and that the country was experiencing meteorological drought, especially in the northern and central parts of the country, where wet season rainfall is the main supply of renewable water resources. In the dry season, rainfall over the country was found to be in deficit for 15 years $(1981,1982$, 1983, 1984, 1985, 1987, 1989, 1990, 1993, 2000, 2002, 2009, 2013, 2014, and 2017) (Fig. 4c). Hence, 1980, 1991, 2004, and 2008 were identified as scanty years in the dry season due to the lack of rainfall in the south and southwestern parts of the country. 
Table 1 Drought classes in Saudi Arabia in different months for 40 years period (1978-2017). In this tabulation, symbols for usual drought $=$ U, moderate drought $=\mathrm{M}$ and severe drought $=\mathrm{S}$ are used

\begin{tabular}{|c|c|c|c|c|c|c|c|c|c|c|c|c|}
\hline \multirow[t]{2}{*}{ Year } & \multicolumn{12}{|c|}{ Drought classes } \\
\hline & Jan & Feb & Mar & Apr & May & Jun & Jul & Aug & Sep & Oct & Nov & Dec \\
\hline 1978 & $\mathrm{UM}$ & & & $\mathrm{U}$ & U M & U M S & & U M & U M S & U M S & UM S & U M S \\
\hline 1979 & & & & U M S & & UM S & U M S & & U M S & & UM S & \\
\hline 1980 & $\mathrm{U} \mathrm{M}$ & & & & & U M S & UM S & U M S & U M S & U M S & & $\mathrm{U} M$ \\
\hline 1981 & $\mathrm{UM}$ & & & U M S & & UM S & $\mathrm{U} \mathrm{M}$ & U M S & U M S & U M S & UMS & U M S \\
\hline 1982 & & & & & & U M S & U M S & U M S & U M S & & & \\
\hline 1983 & & & & & & U M S & U M S & U M S & U M S & U M S & UMS & U M S \\
\hline 1984 & U M S & U M S & & U M & & U M S & U M S & U M S & U M S & U M S & & $\mathrm{U} M$ \\
\hline 1985 & & U M S & $\mathrm{U} \mathrm{M}$ & & & U M S & U M S & U M S & U M S & U M S & & \\
\hline 1986 & $\mathrm{UM}$ & & & & U M S & U M S & U M S & U M S & $\mathrm{U} \mathrm{M}$ & U M S & & \\
\hline 1987 & U M S & U M S & & & & U M S & U M S & & U M S & & U M S & \\
\hline 1988 & & & $\mathrm{U} \mathrm{M}$ & & U M S & U M S & & U M S & U M S & U M S & U M S & \\
\hline 1989 & U M S & & & & U M S & U M S & U M S & U M S & U M S & U M S & & \\
\hline 1990 & & & & & U M & U M S & U M S & U M S & U M S & U M S & U M S & U M S \\
\hline 1991 & & & & & $\mathrm{U} M$ & U M S & U M S & U M S & U M S & & U M & U M S \\
\hline 1992 & & & & & U M & U M S & U M S & & $\mathrm{U} \mathrm{M}$ & U M S & & \\
\hline 1993 & & & & & & U M S & U M S & U M S & U M S & & U M S & \\
\hline 1994 & & U M S & & & & U M S & U M & U M S & $\mathrm{U} \mathrm{M}$ & & & \\
\hline 1995 & U M S & & & & & U M S & & U M & U M S & U M S & U M S & \\
\hline 1996 & & $\mathrm{U} M$ & & & & & U M S & U M S & U M S & U M S & & $\mathrm{U} \mathrm{M}$ \\
\hline 1997 & & U M S & & $\mathrm{U}$ & & $\mathrm{U} \mathrm{M}$ & U M S & U M S & U M S & & & \\
\hline 1998 & & U M S & & & & U M S & U M & & U M S & U M S & U M S & U M S \\
\hline 1999 & & & & U M S & U M S & U M S & U M S & U M S & $\mathrm{U} M$ & U M S & U M S & \\
\hline 2000 & & U M S & U M S & $\mathrm{U} \mathrm{M}$ & & U M S & U M S & U M S & U M S & U M & & \\
\hline 2001 & & U M S & & & U M S & U M S & U M & & U M S & $\mathrm{U} \mathrm{M}$ & UM S & \\
\hline 2002 & & $\mathrm{U} M$ & & & U M S & U M S & U M S & U M S & U M S & U M S & & \\
\hline 2003 & $\mathrm{U} \mathrm{M}$ & U M S & U M & & $\mathrm{U} \mathrm{M}$ & U M S & U M S & & U M S & U M S & & \\
\hline 2004 & & U M S & U M S & & U M S & U M S & U M S & U M S & U M S & U M & $\mathrm{U} \mathrm{M}$ & \\
\hline 2005 & & & & & & U M S & U M S & & U M S & U M S & $\mathrm{U} \mathrm{M}$ & U M S \\
\hline 2006 & U M S & & $\mathrm{U}$ M & & & U M S & U M S & & U M S & & & \\
\hline 2007 & & & $\mathrm{U} \mathrm{M}$ & & $\mathrm{U} M$ & $\mathrm{U} M$ & U M S & U M S & U M S & U M S & U M S & U M S \\
\hline 2008 & & U M S & U M S & $\mathrm{U} \mathrm{M}$ & & U M S & U M S & U M S & U M S & & & U M S \\
\hline 2009 & U M S & U M S & U M S & & & U M S & U M S & U M & U M S & U M S & & \\
\hline 2010 & & & & & & U M S & & U M S & U M S & U M S & U M S & \\
\hline 2011 & & U M S & & & $\mathrm{U} M$ & U M S & U M & $\mathrm{U} M$ & U M S & U M S & & U M S \\
\hline 2012 & U M S & U M S & U M S & & U M S & U M S & U M S & U M S & U M S & U M & & \\
\hline 2013 & & U M S & & & & U M S & U M S & U M S & U M S & U M S & & \\
\hline 2014 & & U M S & & & & U M S & U M S & U M S & U M S & & & \\
\hline 2015 & U M S & U M S & & U M S & $\mathrm{U}$ & U M S & U M S & $\mathrm{U}$ & $\mathrm{U}$ & & & \\
\hline 2016 & U M S & $\mathrm{U}$ & & & $\mathrm{U}$ & U M S & & & U M S & U M S & & U M S \\
\hline 2017 & U M S & & & & & U M S & U M S & U M S & U M S & U M S & UM S & U M S \\
\hline
\end{tabular}

As shown in Fig. 4b, three consecutive years from 1998 to 2000 belong to different rainfall categories: 1998 is in surplus, 1999 is almost in deficit, and 2000 is scanty. To understand in detail the status of these three consecutive years, the spatial distribution of rainfall in and around Saudi Arabia obtained from relatively high-resolution TRMM data is displayed in Fig. 5. In general, Saudi Arabia received less rainfall as compared with neighboring countries to the northeast and southwest, particularly in the dry season that also appears in the annual amount. The annual total rainfall was high in the 
southwestern and central parts of Saudi Arabia in 1998 but was then reduced in 1999 and 2000. It is mainly the wet season rainfall which contributes to surplus rain in 1998 for the abovementioned regions (Fig. 5d). In 1998, heavy rainfall was also observed in the southwest region during the dry season (Fig. 5g). Although relatively heavy rainfall occurred in the center of the Arabian Gulf during the wet season of 2000, reduced rain in the southwest (Fig. 5e) as well as little rain in the dry season (Fig. 5i) caused this year to be classified as scanty. Overall, annual rainfall patterns in 1998, 1999, and 2000 show a similar distribution over the region (Almazroui et al. 2012b). The annual low rainfall (below $80 \mathrm{~mm}$ ) was in the very dry area of Rub Al-Khali, moderate rainfall (above $80 \mathrm{~mm}$ to below $150 \mathrm{~mm}$ ) was in the dry area over central to north of Saudi Arabia, and heavy rainfall (above $150 \mathrm{~mm}$ ) was in the wettest area in the southwest of the Peninsula.

\section{Drought categories for Saudi Arabia}

Meteorological drought categories in Saudi Arabia obtained based on rainfall thresholds (Smakhtin and Hughes 2004) are discussed here.

As a first step, the national average rainfall for each month for the 40-year analysis period was obtained. The data was then categorized into usual ( $\geq 25 \%$ below average), moderate (between 26 and $50 \%$ below average), and severe ( $\geq 50 \%$ below average) droughts as presented in Table 1. In most years, drought occurs in Saudi Arabia during the dry season (June-September). The transition month of October also experienced a drought situation for 29 years $(73 \%)$ of the 40 . In the wet season (November-April), only a few years present a drought situation. Because the amount of monthly rainfall in Saudi Arabia is very low, once a drought is identified for any month, it qualifies almost always for all three categories (usual, moderate, and severe).

Time sequences of the number of drought occurrences (in a month) under different drought categories for the period 1978-2017 are shown in Fig. 6. All drought categories show an insignificant increase in the number of drought occurrences. On average, usual or moderate drought occurred for 7 months (continuous horizontal line) while severe drought occurred for 6 months (dashed horizontal line) in a year. Both usual and moderate droughts occur for $14(35 \%)$ years $(1978,1981,1984,1990,1999,2000,2003,2004$, 2007, 2008, 2009, 2011, 2012, and 2017) with above an average number of drought months (7). In contrast, severe drought occurs for 11 (28\%) years (1981, 1983, 1984, 1989, 1990, 1999, 2004, 2008, 2009, 2012, and 2017) with an above average number of drought months (6). Both usual and moderate droughts occur for a maximum number of drought months (9) for the years 1981, 1984, 2004, 2007, and 2012. Therefore, to understand the seasonal dependency of rainfall, drought years were identified from the time series analysis and investigated in detail using different datasets to construct the spatial distribution of rainfall patterns for the four example years of 1981, 1984, 2004, and 2007.

Case-1 (1981) To highlight the drought situation in the year 1981, the spatial distribution of seasonal rainfall obtained from the observed, CMAP, and CRU data is displayed in Fig. 7. The rainfall in 1981 was low in Saudi Arabia as compared to the neighboring countries of Eretria and Iran. In that year, in Saudi Arabia, the annual average rainfall was close to the lower limit of the deficit range $(\sim 20 \%$ below normal) and a deficit was detected in the dry season (see Fig. 4). In the wet season, the CMAP and CRU data show large rainfall amounts in the southwest and central to northern regions compared to the normal year of 1999 (see Fig. 5). The observational data show a very similar distribution to that obtained from the CMAP and CRU data. Therefore, due to the wet season rainfall distribution, 1981 cannot be identified as a drought year. The dry season rainfall distribution obtained from observations shows less rainfall in the southwest region of the country in 1981. A similar result is obtained from CMAP and CRU data. In this year, severe drought occurs for 7 months (see Fig. 6). Hence, it is concluded that the lack of dry season rainfall in the southwest region in 1981 is
Fig. 6 Time sequences of drought frequency (in months) under different classes in Saudi Arabia for the period 1978-2017. Then, usual ( $\geq 25 \%$ below normal), moderate $(\geq 26$ and $<50 \%$ below normal), and severe ( $\geq 50 \%$ below normal) droughts are used to identify drought class over the country

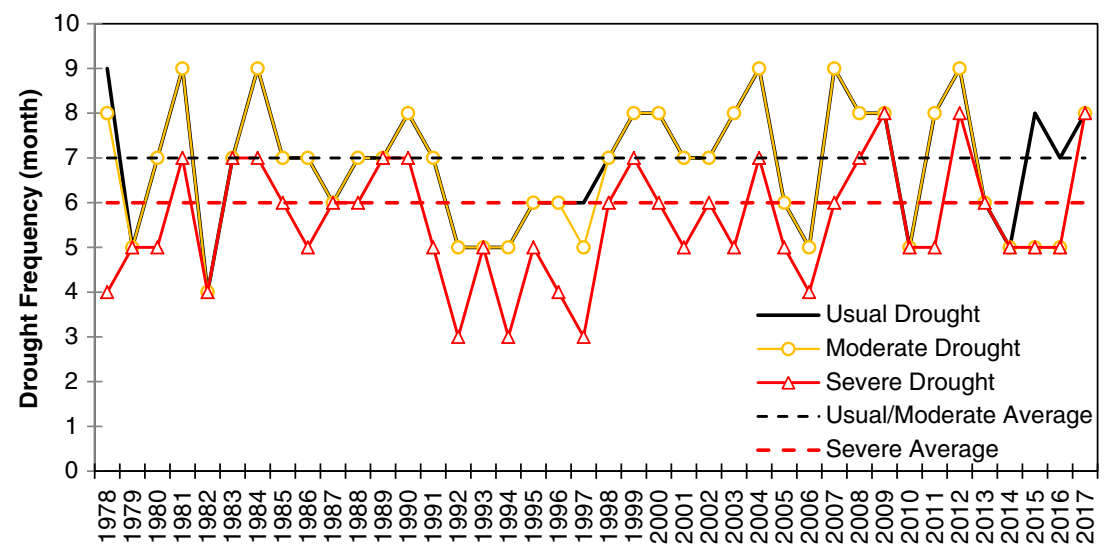


Fig. 7 The wet (left panels) and dry (right panels) season rainfalls obtained from the observed (top panels) CMAP (2nd row), and CRU (bottom panels) datasets for the year 1981. Rainfall amount below $1 \mathrm{~mm}$ is not shown in the legend a Wet season Obs 1981

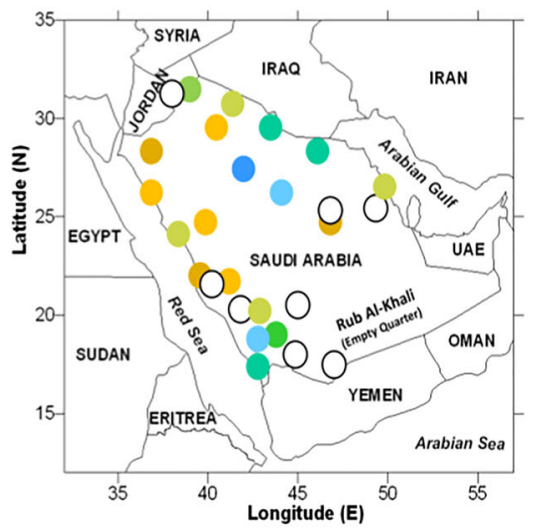

C Wet season CMAP 1981

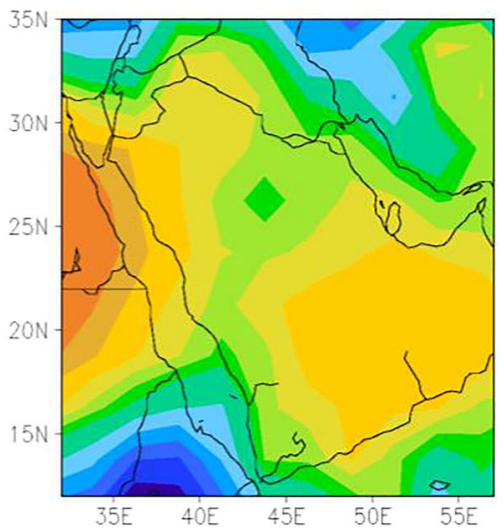

e Wet season CRU 1981

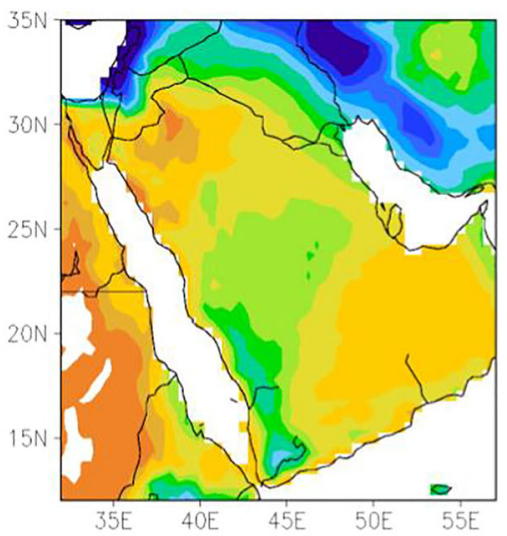

b Dry season Obs 1981

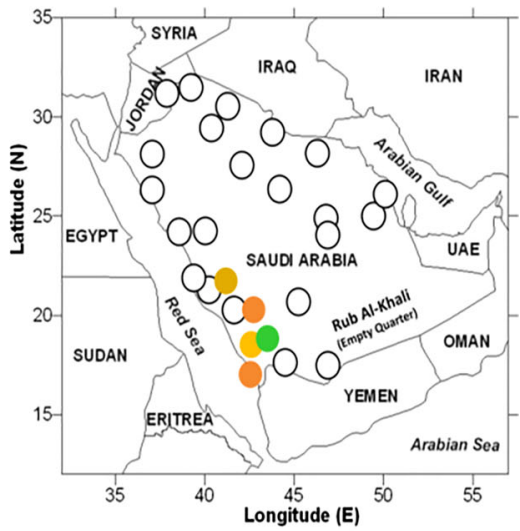

d Dry season CMAP 1981

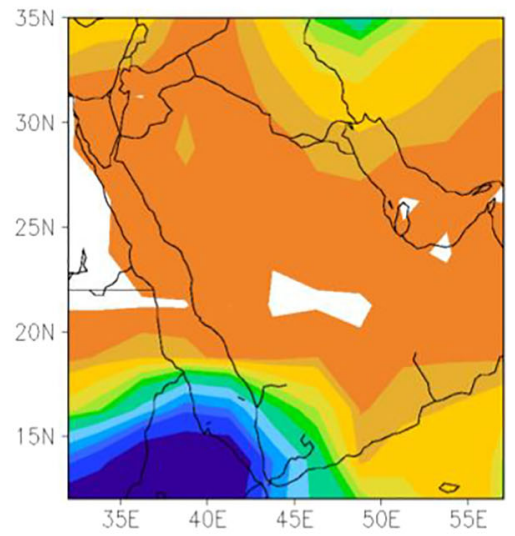

f Dry season CRU 1981

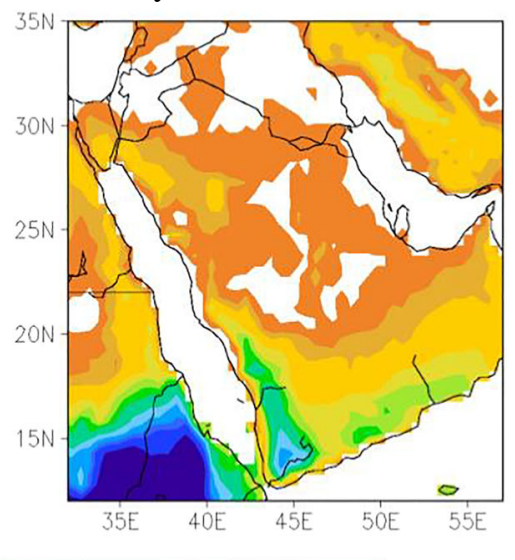

$1 \quad 10 \quad 20 \quad 40 \quad 60 \quad 80 \quad 100 \quad 150 \quad 200 \quad 250 \quad 300400$

responsible for the meteorological drought that year over Saudi Arabia. This is consistent with the deficit rainfall discussed earlier (see Fig. 4c).

Case-2 (1984) As discussed above, the annual rainfall for 1984 is classed as in deficit, even though both wet and dry seasons were close to the scanty classification (Fig. 4). Therefore, to highlight the drought situation during 1984, the spatial distribution of seasonal rainfall obtained from the observed, CMAP, and CRU data is shown in Fig. 8. In 1984, the wet season rainfall over Iran and both the wet and dry season rainfalls over Eretria are much higher than over Saudi Arabia. In this year, the annual average rainfall in Saudi Arabia is within the deficit range ( $\sim 20 \%$ below normal) and a deficit is detected in the wet season (see Fig. 4). Figure 8 a shows clear evidence of a lack of wet season rainfall in the observed data for 1984. In the wet season, the CMAP and CRU data both show small rainfall amounts in the southwest and central-to-northern regions 
Fig. 8 The wet (left panels) and dry (right panels) season rainfalls obtained from the observed (top panels), CMAP (2nd row), and CRU (bottom panels) datasets for the year 1984. Rainfall amount below $1 \mathrm{~mm}$ is not shown in the legend a Wet season Obs 1984

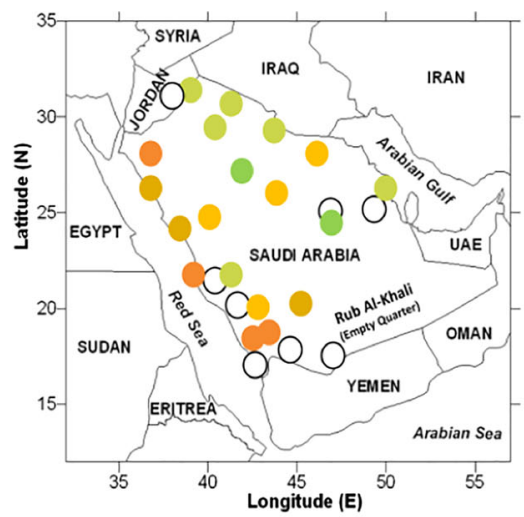

C Wet season CMAP1984

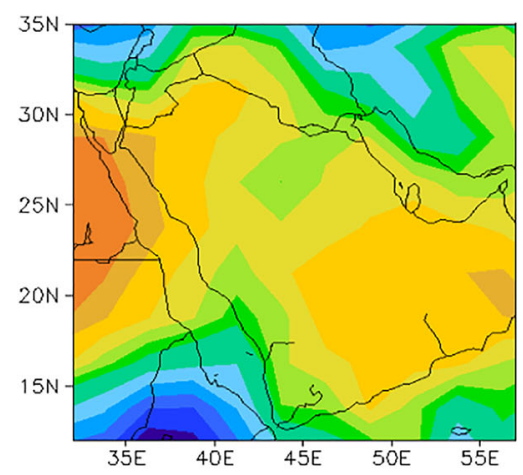

e Wet season CRU 1984

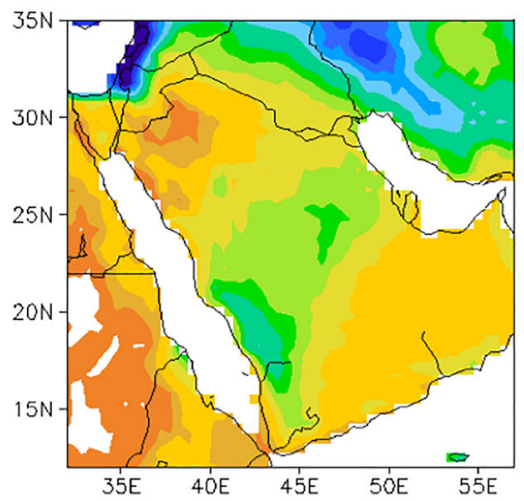

b Dry season Obs 1984

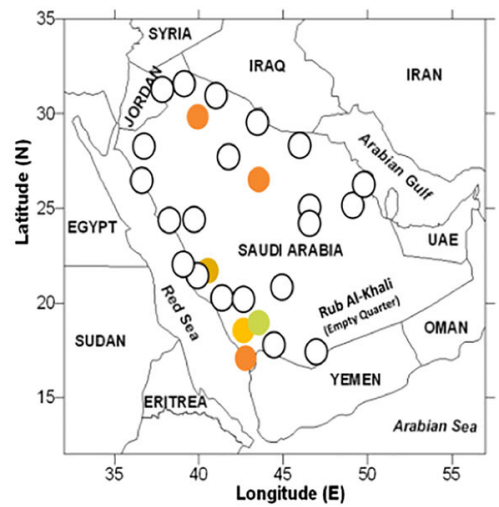

d Dry season CMAP 1984

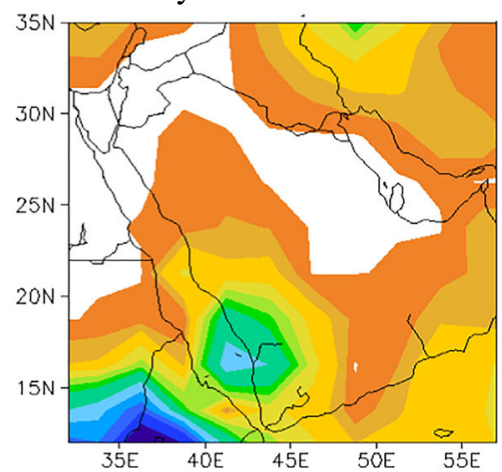

f Dry season CRU 1984

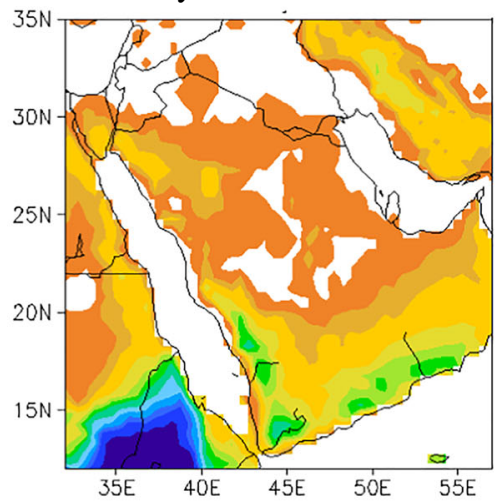

$1 \quad 10 \quad 20 \quad 40 \quad 60 \quad 80 \quad 100 \quad 150200 \quad 250300400$

compared to the normal year, 1999 (see Fig. 5). The coarse resolution CMAP data cannot detect this very well, but the relatively high-resolution CRU clearly captures the lack of wet season rainfall for 1984 in the data. Analysis of dry season gridded rainfall data shows a very similar distribution to observations in 1984 (Fig. 8b). The CMAP data show larger rainfall amounts in the southwest region, and the CRU data shows very similar totals to CMAP. Severe drought occurs for 7 months during this year (see Fig. 6). Therefore, it is concluded that the 1984 drought over Saudi Arabia was due to a lack of wet season rainfall as discussed earlier (see Fig. 4b).
Case-3 (2004) As discussed above, the time series obtained from the observed data identified 2004 as falling in the usual category of rainfall for the wet season and the scanty category for the dry season (see Fig. 4). Figure 9 displays the wet and dry season rainfall obtained from the observed, CMAP, CRU, and TRMM datasets for 2004. The highest rainfall in 2004 is observed to the northeast in the wet season and to the southwest in the dry season while very little rain falls over Saudi Arabia. The observed data shows that the wet season rainfall in 2004 is close to average. The TRMM dataset shows rainfall all over the country. The dry season rainfall in 2004 was very 
Fig. 9 The wet (left panels) and dry (right panels) season rainfalls obtained from the observed (top panels), CMAP (2nd row), and CRU (bottom panels) datasets for the year 2004. Rainfall amount below $1 \mathrm{~mm}$ is not shown in the legend a Wet season Obs 2004

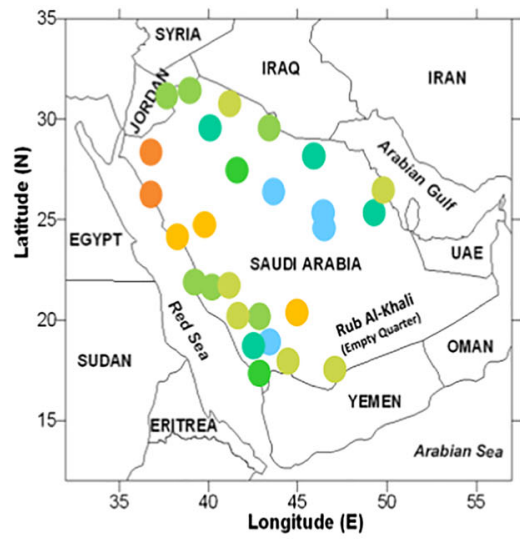

C Wet season CMAP 2004

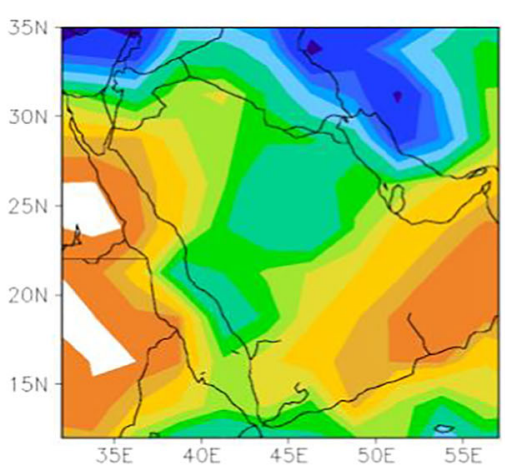

e Wet season CRU 2004

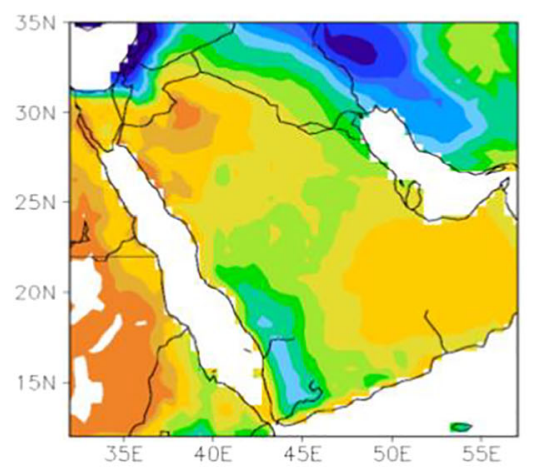

g Wet season TRMM 2004

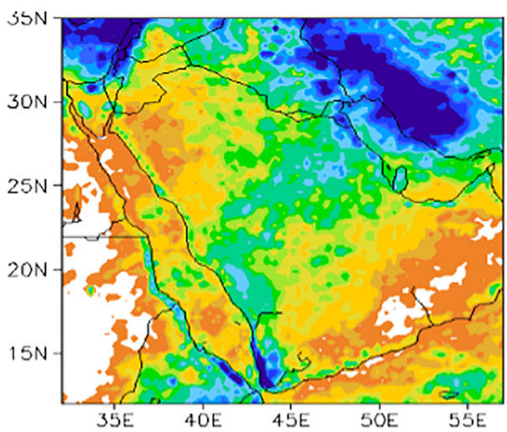

b Dry season Obs 2004

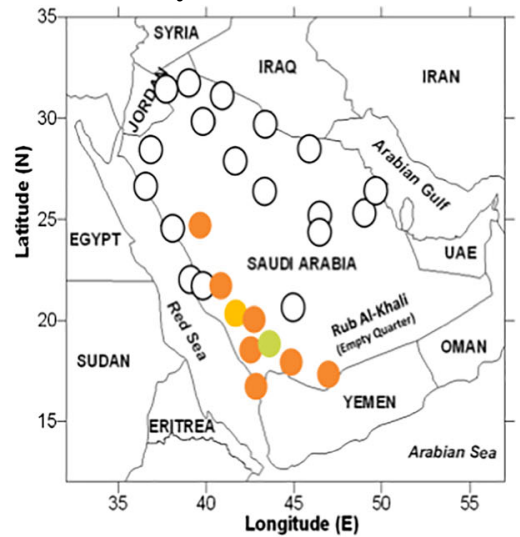

d Dry season CMAP 2004

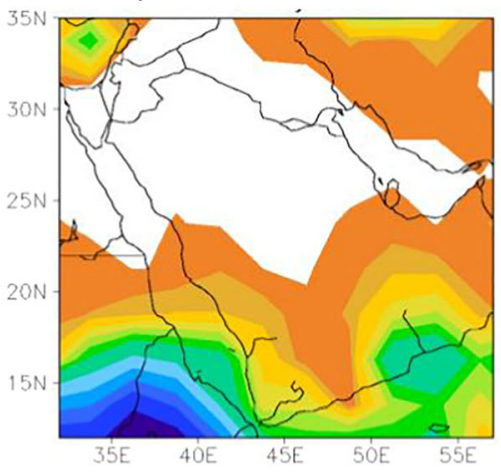

f Dry season CRU 2004

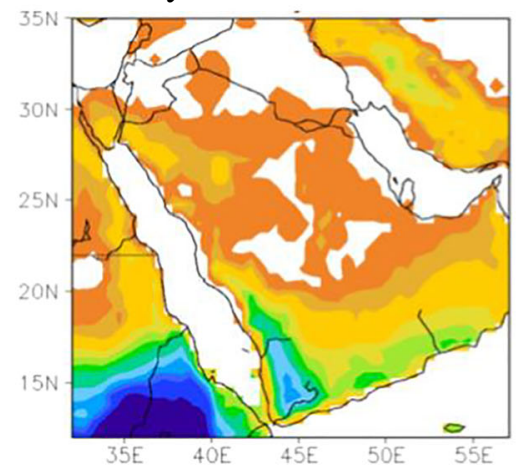

h Dry season TRMM 2004

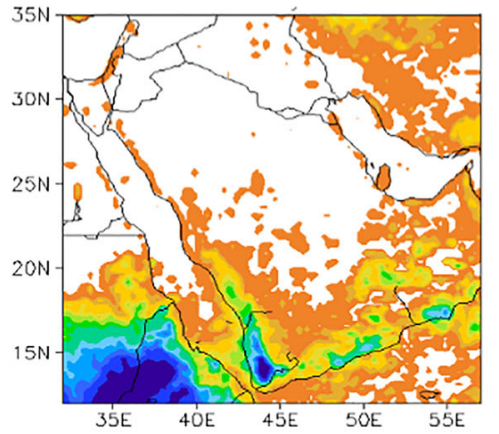

$1 \quad 10 \quad 20 \quad 40 \quad 60 \quad 80 \quad 100150200 \quad 250300400$ 
Fig. 10 The wet (left panels) and dry (right panels) season rainfalls obtained from the observed (top panels), CMAP (2nd row), and CRU (bottom panels) datasets for the year 2007. Rainfall amount below $1 \mathrm{~mm}$ is not shown in the legend a Wet season Obs 2007

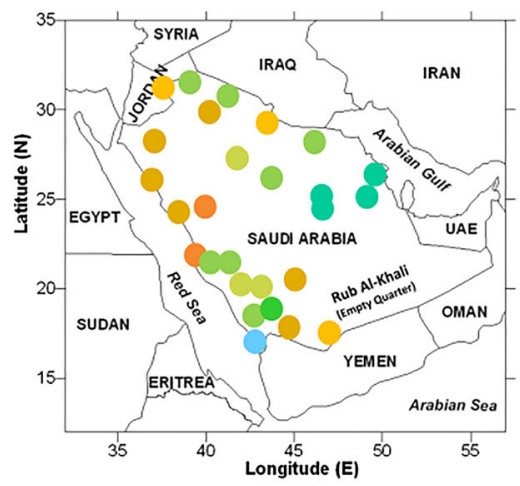

C Wet season CMAP 2007

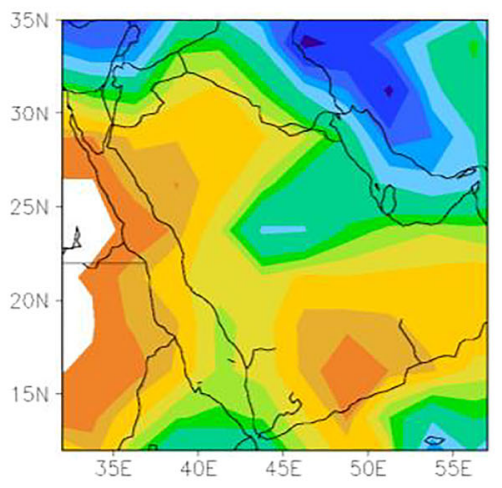

e Wet season CRU 2007

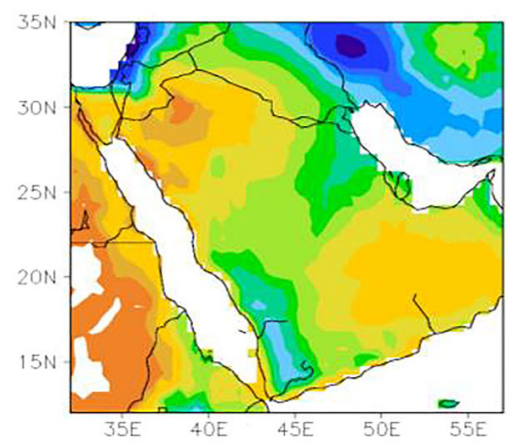

g Wet season TRMM 2007

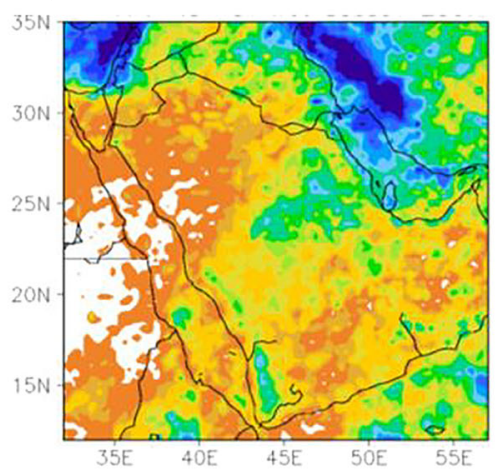

b Dry season Obs 2007

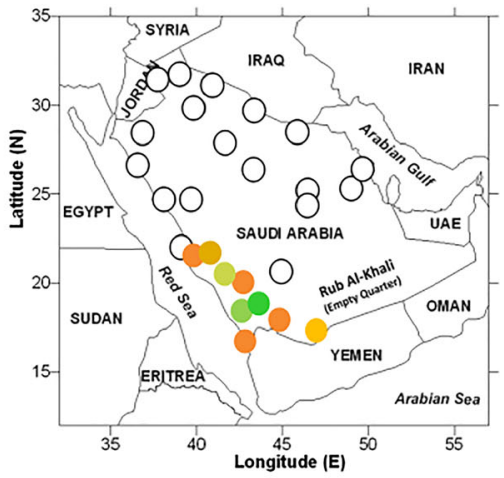

d Dry season CMAP 2007

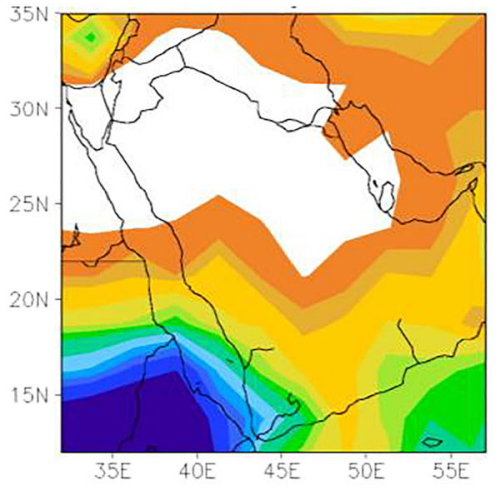

f Dry season CRU 2007

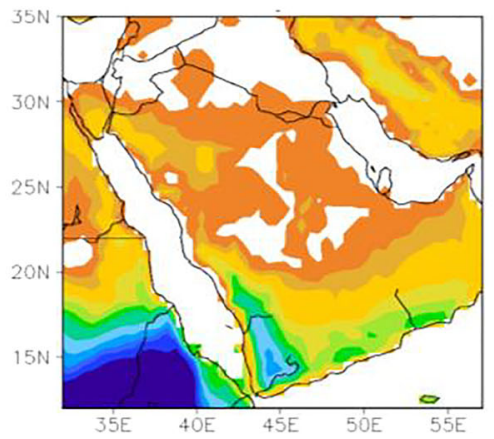

h Dry season TRMM 2007

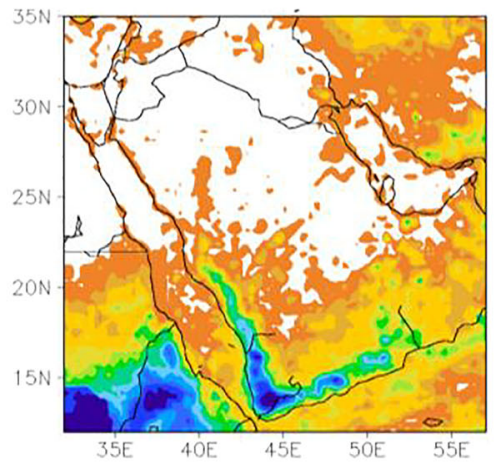


Table 2 Rainfall classes in Saudi Arabia obtained from 27 stations for 40 years (1978-2017). In this tabulation, total station locations are counted $1080(27 \times 40)$ individual stations

\begin{tabular}{llll}
\hline & Annual & Wet season & Dry season \\
\hline Below normal & 606 & 636 & 833 \\
Above normal & 418 & 388 & 191 \\
Total & 1024 & 1024 & 1024 \\
Usual & 221 & 208 & 63 \\
Deficit & 298 & 288 & 80 \\
Scanty & 174 & 223 & 721 \\
Surplus & 331 & 305 & 160 \\
Total & 1024 & 1024 & 1024 \\
Missing stations & 56 & 56 & 56 \\
Total stations & 1080 & 1080 & 1080 \\
\hline
\end{tabular}

low all over Saudi Arabia, as determined from all the data sources. In the dry season, the CMAP and TRMM data show low rainfall amounts in the southwest region compared to the normal year of 1999 (see Fig. 5). This is consistent with the scanty classification identified for 2004 from the time series analysis (see Fig. 4c). In this year, severe drought occurs for 7 months (see Fig. 6). So, it is evident that the lack of dry season rainfall is responsible for the drought situation in 2004 over the country.

Case-4 (2007) The time series analysis identified a deficit of rainfall in 2007, 2008, and 2009 at the annual scale (see Fig. 4a). However, 2007 was identified as usual during the wet and dry seasons (see Fig. 4b, c). The spatial distribution of seasonal rainfall obtained from all data sources used is shown in Fig.
10. The distribution of rainfall in 2007 shows a common phenomenon that rainfall over Saudi Ara is lower than over neighboring Iran and Eretria. The wet season rainfall obtained from the observed data shows average rainfall over the country for 2007. Similar results were obtained from the CMAP and TRMM datasets. Both the datasets agree on average rainfall in 2007, as discussed above (see Fig. 4b, c). The dry season rainfall distribution obtained from the observed data shows almost no rain over the country except for small patches in the southwest area in 2007 (Fig. 10b). In this season, the northern regions are completely dry. In the southwestern regions, there was also very little rain in the dry season except for only two stations. The CMAP, CRU, and TRMM data are in agreement with this condition over the country. In this year, severe drought occurs for 6 months (see Fig. 6). Therefore, the lack of rainfall during the dry season is the cause of drought in 2007 over Saudi Arabia.

\section{Discussion}

Analysis of these four cases showed that drought events over Saudi Arabia occur mostly due to a deficit of rainfall in the dry season. All rainfall categories in Saudi Arabia, at annual and seasonal scales for 1978-2017, are summarized in Table 2 taking into account the distribution of the 27 stations over 40 years, i.e., $1080(=27 \times 40)$ individual station points. At the annual scale, there are the $298(29 \%)$ of station points in deficit and $331(32 \%)$ in surplus. The usual rainfall category was obtained for a relatively small number of station points $(221=22 \%)$, whereas the scanty category was found only for $174(17 \%)$ station points. During both wet and dry seasons,
Fig. 11 Annual cycle of drought frequency (in year) associated to different classes obtained based on rainfall threshold in Saudi Arabia for 40 years analysis period (1978-2017)

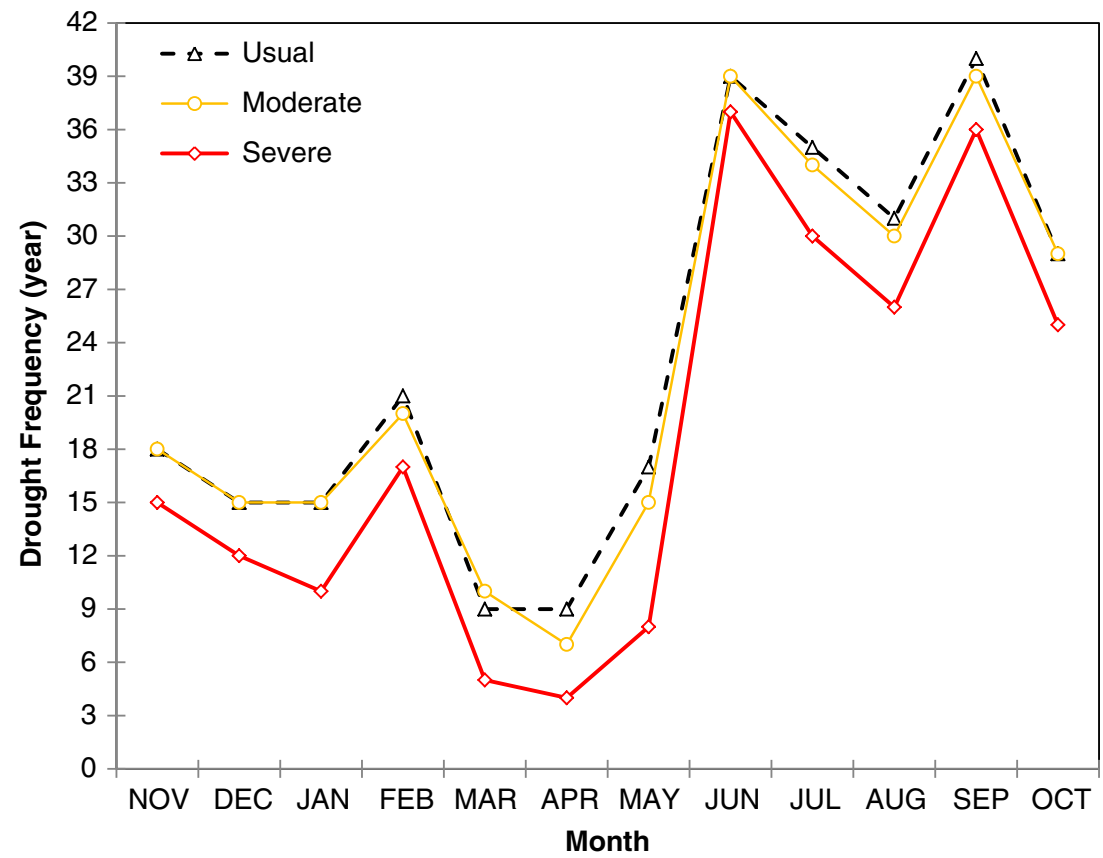


Table 3 Summary of the four cases of meteorological drought years in Saudi Arabia analyzed during 1978-2017

\begin{tabular}{lllll}
\hline Case & Drought year & Season & Region & Remark \\
\hline 1 & 1981 & Dry & Southwest & Dry season rainfall causes drought \\
2 & 1984 & Wet & Southwest & Wet season rainfall causes drought \\
3 & 2004 & Dry & Southwest & Dry season rainfall causes drought \\
4 & 2007 & Dry & Country & Dry season rainfall causes drought \\
\hline
\end{tabular}

the number of stations below normal rainfall increased and those with above normal decreased greatly. In the dry season, the scanty category applied to the highest number $(721=$ $70 \%$ ) of station points, while in the wet season, a surplus was found at the highest number $(305=30 \%)$ of station points. This implies that in Saudi Arabia, drought mainly occurred due to a shortfall in the dry season, and surpluses were due to heavy rainfall in the wet season.

The annual cycle of drought frequency associated with different drought categories in Saudi Arabia is displayed in Fig. 11. Both the usual and moderate categories show the same number of drought years for all months, except that the moderate category has 2 years less for April, the last month of the wet season. The severe category also follows the patterns of usual and moderate droughts. November, the beginning of the wet season, shows a decreasing trend in, the number of drought years in all categories. Next in rank is April, the end of the wet season. February is an exception, being ranked higher than both in January and March. After the transition month of May, the number of drought years sharply increased for all categories in June, the beginning of the dry season. In June, both usual and moderate drought categories occurred in 39 years (98\%), while the severe category occurred in 37 years (93\%), out of 40. In July and August, the number of drought years slightly declined, although at the end of the dry season, the usual category reached the maximum number of 40 years $(100 \%)$, while severe also reached $90 \%$. The tendency in the transition month of October is towards a reduction in all categories. Overall, lower rainfall during the dry season is seen to

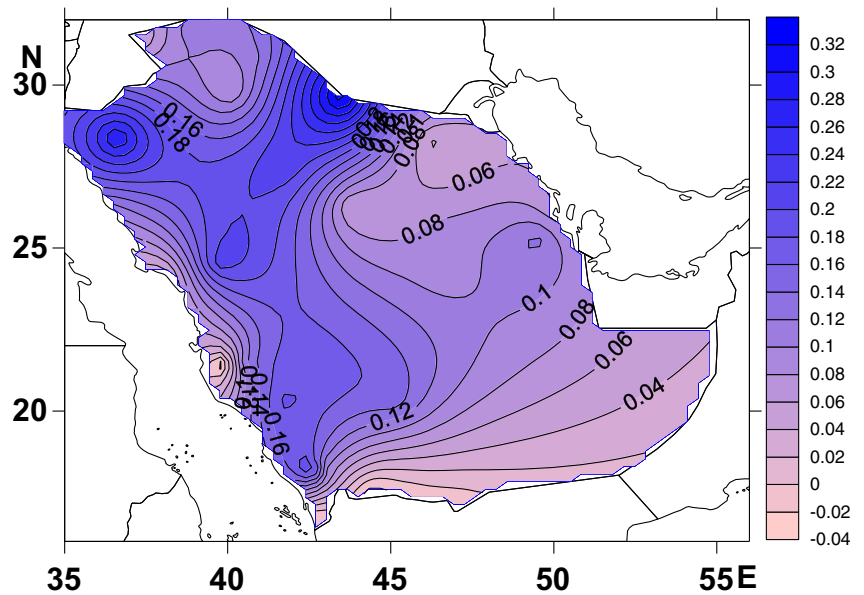

be responsible for drought conditions in Saudi Arabia, supporting the previous conclusion. Results show that for the last months of the wet season, April is less prone, while the first and last months of the dry season (June and September) are more prone to drought.

The cause of meteorological drought over Saudi Arabia analyzed for four cases between 1978 and 2017 is summarized in Table 3. Of the four cases analyzed, the drought situation in three of them is due to dry season shortfall while wet season shortfall is responsible for the fourth. The combination of shortfalls in both wet and dry seasons is not found in any of the four cases studies. Hence, it is concluded that the rainfall time series obtained from the station observation accurately represents the meteorological drought conditions over Saudi Arabia and these conclusions are supported by the CMAP, CRU, and TRMM datasets.

In order to demonstrate the drought situation in Saudi Arabia, commonly used drought indices such as SPI and PDSI are calculated from observations at 27 station locations across Saudi Arabia (Fig. 12). More information about the drought indices may be seen in some literaures, for instance Dash et al. (2012), Gidey et al. (2018a, b), and Mustafa and Rahman (2018). The spatial distributions of SPI- and PDSIbased drought indices show that drought is pervasive in the southern and northeast regions of Saudi Arabia. However, the situation may change in the future because climate model simulations show a likely increase in precipitation over the south and southeast and a decrease in the northwest of the Peninsula in the projection period (Almazroui et al. 2017b,

Fig. 12 Spatial distributions of drought indices SPI (left panel) and PDSI (right panel) obtained from observed data

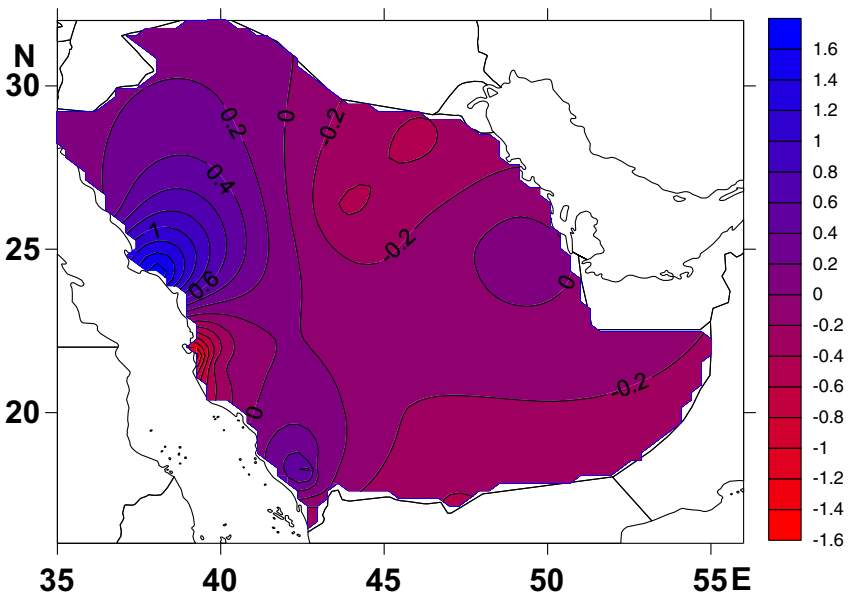


c). The results of the current study may not apply because detailed analyses for mild drought, moderate drought, severe drought, and extreme drought were not performed here. Also to better understand and project the drought situation in Saudi Arabia, it is suggested that drought indices be calculated using climate model output, for example, with Saudi-KAU GCM data (Almazroui et al. 2017a; Ehsan et al. 2017). So far, the use of climate model data in calculating drought indices has been a challenging task because of the limitations of climate simulations. Therefore, the utility of climate model output, along with some validation work, will be presented in a separate document.

\section{Conclusions}

The purpose of this paper is to identify drought conditions for Saudi Arabia using observed data for the present climate (1978-2017). Rainfall data is helpful for understanding meteorological drought phenomena and their characteristics in the region. Using rainfall thresholds, the categories of deficit, scanty, and surplus were applied to data at both annual and seasonal scales. Based on monthly data of rainfall thresholds, the drought categories of usual, moderate, and severe were identified. Results show that for the 40-year analysis period, annual rainfall was below normal for 25 years, of which 10 years show deficit rainfall at the annual scale. The wet season experienced 7 deficit and 3 scanty years while the dry season had 15 deficit and 4 scanty years. Usual and moderate droughts occur for almost same number of months in a year. Patterns of the monthly distribution of severe drought cases follow almost the same distribution pattern as usual/moderate droughts. Four drought cases (1981, 1984, 2004 and 2007) within the country are discussed in detail. Of the four, three were due to a deficit in rainfall in the dry season. A combined shortfall in both wet and dry seasons causing drought phenomena was not found. Considering the distribution of 27 stations over 40 years $(1080=27 \times 40)$ individual station points), we found that the dry season is responsible for the scanty category and the wet season for the surpluses throughout the country. All of the drought categories in Saudi Arabia occurred mostly during the dry season, with fewer during the wet season. The drought index calculations show the current pattern of drought over the region. The next step is to obtain drought indices for the near future (e.g., 2021-2050) and far future (2071-2100) using climate model simulations, and this will be documented in a separate paper.

Acknowledgments The authors would like to acknowledge the GAMEP of Saudi Arabia for providing the rainfall data. The CMAP, CRU, and TRMM datasets were obtained from their websites. Computation for the work described in this paper was performed using Aziz Supercomputer at King Abdulaziz University's High Performance Computing Center, Jeddah, Saudi Arabia.
Open Access This article is distributed under the terms of the Creative Commons Attribution 4.0 International License (http:// creativecommons.org/licenses/by/4.0/), which permits unrestricted use, distribution, and reproduction in any medium, provided you give appropriate credit to the original author(s) and the source, provide a link to the Creative Commons license, and indicate if changes were made.

\section{References}

Abdullah MA, Al-Mazroui MA (1998) Climatological study of the southwestern region of Saudi Arabia. I. Rainfall analysis. Clim Res 9: 213-223

Almazroui M (2011) Calibration of TRMM rainfall climatology over Saudi Arabia during 1998-2009. Atmos Res 99:400-414

Almazroui M, Islam MN, Jones PD, Athar H, Rahman MA (2012a) Recent climate change in the Arabian Peninsula: seasonal rainfall and temperature climatology of Saudi Arabia for 1979-2009. Atmos Res 111:29-45

Almazroui M, Islam MN, Athar H, Jones PD, Rahman MA (2012b) Recent climate change in the Arabian Peninsula: annual rainfall and temperature analysis of Saudi Arabia for 1978-2009. Int J Climatol 32:953-966

Almazroui M, Tayeb O, Mashat AS, Yousef A, Al-Turki YA, Abid MA, Bafail AO, Ehsan MA, Zahed A, Rahman MA, Mohorji AM, Kang IS, Noaman A, Omar M, Al-roqi AM, Ammar K, Al-Ghamdi AS, Hussein MA, Katib I, O’Brien E, Aljohani NR, Islam MN, Alsaedi A, Yang YM, Alkhalaf AK, Ismail M, Mashat A, Kucharski F, Assiri M, Ibrahim S, Tippett M, Rashid IU, Kamil S, Alahmadi A, Atif RM, Bajunaid MA, Hantoush AS (2017a) Saudi-KAU coupled global climate model: description and performance. Earth Syst Environ 1(1). https://doi.org/10.1007/s41748-017-0009-7

Almazroui M, Islam MN,-Sajjad S, Alkhalaf AK, Dambul R (2017b) Assessment of uncertainties in projected temperature and precipitation over the Arabian Peninsula using three categories of Cmip5 multimodel ensembles. Earth Syst Environ 1: 23. https://doi.org/ 10.1007/s41748-017-0027-5, 20

Almazroui M, Islam MN, Saeed F, Alkhalaf AK, Dambul R (2017c) Assessing the robustness and uncertainties of projected changes in temperature and precipitation in AR5 Global Climate Models over the Arabian Peninsula. Atmos Res 194:202-213

Banerji S, Chabra BM (1964) Drought characteristics and estimating probabilities of their occurrences. In Surface waters symposium. Publication No. 63: 189-192, Belgium. Belgium: WMO/IASH

Bates CG (1935) Climatic characteristics of the plains region. In Possibilities of shelterbelt planting in the plains region, ed. $\mathrm{M}$. Silcox. Washington, D.C

Bhalme HN, Mooley DA (1980) Large-scale droughts/floods and monsoon circulation. Mon Weather Rev 108:1197-1211

Bruwer JJ (1990) Drought policy in the Republic of South Africa. In Proceedings of the SARCCUS Workshop on Drought, June 1989. ISBN 0949986240

Dash BK, Rafiuddin M, Khanam F, Islam MN (2012) Characteristics of meteorological drought in Bangladesh. Nat Hazards 64:1461-1474

Ehsan MA, Almazroui M, Yousef A (2017) Impact of different cumulus parameterization schemes in Saudi-KAU AGCM. Earth Syst Environ 1(1):1-17. https://doi.org/10.1007/s41748-017-0003-0

Gidey E, Dikinya O, Sebego R, Segosebe E, Zenebe A (2018a) Modeling the spatio-temporal meteorological drought characteristics using the Standardized Precipitation Index (SPI) in Raya and its environs, Northern Ethiopia. Earth Syst Environ 2:281-292. https://doi.org/ 10.1007/s41748-018-0057-7

Gidey E, Dikinya O, Sebego R, Segosebe E, Zenebe A (2018b) Using drought indices to model the statistical relationships between meteorological and agricultural drought in Raya and its environs, 
Northern Ethiopia. Earth Syst Environ 2:265-279. https://doi.org/ 10.1007/s41748-018-0055-9

Harris I, Jones PD, Osborn TJ, Lister DH (2014) Updated high-resolution grids of monthly climatic observations - the CRU TS3.10 dataset. Int J Climatol 34:623-642

IPCC (2007) Climate change 2007. The physical sciences basis Contribution of Working Group 1 to the Fourth Assessment Report of the Intergovernmental Panel on Climate Change ed S Solomon, D Qin, M Manning, Z Chen, M Marquis, K B Averyt, M Tignor and H L Miller (Cambridge: Cambridge University Press) p 966

IPCC (2013) In: Stocker TF, Qin D, Plattner GK, Tignor M, Allen SK, Boschung J, Nauels A, Xia Y, Bex V, Midgley PM (eds) Climate change 2013: the physical science basis Contribution of Working Group I to the Fifth Assessment Report of the Intergovernmental Panel on Climate Change. Cambridge University Press, Cambridge Islam MN, Almazroui M, Dambul R, Jones PD, Alamoudi AO (2015) Long-term changes in seasonal temperature extremes over Saudi Arabia during 1981-2010. Int J Climatol 35:1579-1592

Kummerow C, Simpson J, Thiele O, Barnes W, Chang ATC, Stocker E, Adler RF, Hou A, Kakar R, Wentz F, Ashcroft P, Kozu T, Hong Y, Okamoto K, Iguchi T, Kuroiwa H, Im E, Haddad Z, Huffman G, Ferrier B, Olson WS, Zipser E, Smith EA, Wilheit TT, North G, Krishnamurti T, Nakamura K (2000) The status of the Tropical Rainfall Measuring Mission (TRMM) after two years in orbit. J Appl Meteorol 39:1965-1982

Lioubimtseva E (2004) Climate change in arid environments: revisiting the past to understand the future. Progr Phy Geogr 28(4):502-530

McKee TB, Doesken NJ, Kleist J (1993) The relationship of drought frequency and duration to time scales. Preprints, 8th Conference on Applied Climatology, 17-22 January, Anaheim, CA, 179-184

Mitchell TD, Carter TR, Jones PD, Hulme M, New M (2004) A comprehensive set of high-resolution grids of monthly climate for Europe and the globe: the observed record (1901-2000) and 16 scenarios (2001-2100), Tyndall Centre Working Paper No. 55

Mustafa A, Rahman G (2018) Assessing the spatio-temporal variability of meteorological drought in Jordan. Earth Syst Environ 2:247-264. https://doi.org/10.1007/s41748-018-0071-9

New M, Hulme M, Jones P (2000) Representing twentieth-century space-time climate variability. Part II: development of 1901-1996 monthly grids of terrestrial surface climate. J Clim 13(13):22172238

Oladipo EO (1985) A comparative performance analysis of three meteorological drought indices. Int J Climatol 5:655-664

Palmer WC (1965) Meteorological drought. U.S. Weather Bureau Res. Paper No 45

Ragab R, Prudhomme C (2000) Climate change and water resources management in the southern Mediterranean and Middle East countries. The Second World Water Forum, 17-22, March 2000, The Hague

Ramdas DA (1950) Rainfall and agriculture. Indian Journal of Meteorology and Geophysics 1(4):262-274

Seidel DJ, Qiang FU, Randel WJ, Reichler TJ (2008) Widening of the tropical belt in a changing climate. Nat Geosci 1:21-24

Shongwe ME, van Oldenborgh GJ, van den Hurk B, van Aalst M (2011) Projected changes in extreme precipitation in Africa under global warming, part II: East Africa. J Clim 24:3718-3733

Smakhtin VU, Hughes DA (2004) Review, automated estimation and analyses of drought indices in South Asia. Working paper 83, Colombo, Sri Lanka, International Water Management Institute, pp 5-6. ISBN: 92-9090-578-6

Xie P, Arkin PA (1997) Global precipitation: a 17-year monthly analysis based on gauge observations, satellite estimates, and numerical model outputs. Bull Am Meteorol Soc 78:2539-2558 